\section{Gesundheit im Ländervergleich}

Das deutsche Gesundheitssystem bietet seinen Versicherten im europäischen Vergleich die kürzesten Wartezeiten, den schnellsten Zugang zu innovativen Arzneimitteln, die freie Arztwahl sowie einen umfangreichen Leistungskatalog. Das geht aus einer Untersuchung des Wissenschaftlichen Instituts der PKV (WIP) hervor. Demnach erhalten 76\% der Patienten hierzulande am selben Tag der Anfrage oder am nächsten Tag einen Arzttermin. In häufig mit Deutschland verglichenen Staaten liege diese Quote darunter: in den Niederlanden bei $63 \%$, in Schweden bei 58\% oder in Frankreich bei $57 \%$.

\section{Meningitis gehäuft in der Toskana}

In der Toskana wurden letztes Jahr 33 Fälle von Meningokokken-Meningitis registriert; sechs Menschen sind daran gestorben. Anfang November erkrankte z.B. in Pisa ein 9-jähriges Mädchen. Im Oktober musste in einer Klinik in der Provinz Prato ein junger Mann intensivmedizinisch behandelt werden. Bereits im Jahr zuvor waren ungewöhnlich viele Infektionen gemeldet worden. Als Erreger wurden Meningokokken der Serogruppe C identifiziert. Impfkampagnen für Jugendliche und Erwachsene wurden durchgeführt. Eine offizielle Impfempfehlung für Touristen gibt es nicht; bei Reisenden in die Region kann der Schutz aber erwogen werden.

www.aerztezeitung.de

\section{Gut gewappnet auf Reisen gehen}

Der Sommer steht vor der Tür und mit ihm häufig der langersehnte Jahresurlaub. Neben sorgfältiger Planung des Urlaubsziels stellt sich vor allem chronisch kranken Patienten die Frage: Wie schütze ich mich am besten, um die wohlverdiente Auszeit zu genießen? Was gehört in die Reiseapotheke, welche Verhaltensregeln sind zu beachten und wie beuge ich am besten vor? Empfehlungen hierzu lesen Sie in unserem Schwerpunkt „Reisemedizin".

Claudia Daniels Redakteurin

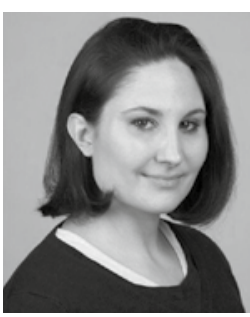

\title{
Flughäfen sind auch ein Umsteigepunkt für Bakterien
}

Gefährliche Keime reisen mit dem internationalen Flugverkehr von einem Kontinent zum anderen. Eine Studie zeigte, dass sie sich besonders in Flughafen-Toiletten breit machen: Insgesamt 400 Türklinken von 136 Flughäfen in 59 Ländern haben Wissenschaftler hierfür auf Keime untersucht. Von den Türklinken-Abstrichen wurden die Keime auf Spezialnährmedien angezüchtet und identifiziert. Die Forscher analysierten die Spezies und das Erbgut jedes gefundenen Erregers. Die
Annahme, dass Fluggäste auch sogenannte multiresistente "Superkeime“ von Reisen in ferne Länder in ihr Heimatland mitbringen können, wurde durch die Funde bestätigt. „Einer der gefundenen MRSAErreger, festgestellt in einer Probe aus $\mathrm{Pa}$ ris, war höchst ungewöhnlich für diese Region. Hauptsächlich kommt er in Indien vor. Er muss also vom Menschen dorthin gebracht worden sein“, so ein Experte.

Clinical Microbiology and Infection 2016; 22(12):1010

\section{Vor Fernreisen gegen Tollwut impfen!}

Deutschland ist seit 2008 frei von klassischer Wildtollwut, lediglich in Fledermäusen zirkuliert das Virus noch. Reisende können sich aber weiterhin infizieren - vor allem in Afrika und Asien. Ob streunende Hunde, Affen, Katzen oder Fledermäuse in vielen Ländern Afrikas, Asiens oder Lateinamerikas übertragen Säugetiere die Erreger. Dabei ist nicht einmal ein Biss nötig. Bereits wenn der Speichel von infizierten Tieren in Berührung mit kleinen, offenen Hautstellen kommt, können die Tollwutviren in den menschlichen Organismus gelangen. In der Regel beträgt die Inkubati- onszeit drei bis acht Wochen. In Einzelfällen kann es mehrere Jahre dauern, bis die Krankheit ausbricht. Prof. Dr. Tomas Jelinek, Wissenschaftlicher Leiter des Centrums für Reisemedizin (CRM), rät, sich schon vor einer Reise vollständig mit einem modernen Zellkulturimpfstoff impfen zu lassen. Für einen vollständigen Schutz wird die Impfung in drei Dosen innerhalb von mehreren Wochen verabreicht. Bei der Schnellimmunisierung ist es auch möglich, innerhalb von einer Woche zu impfen.

www.crm.de/laender

\section{Mit Kleinkindern nicht in die Tropen!}

Vor allem für Babys und kleine Kinder sind nicht alle Reiseziele geeignet. Das wird im Zuge des Trends zu Elternzeitreisen immer bedeutender. Von Reisen in Malariagebiete rät das Centrum für Reisemedizin (CRM) mit Babys und Kleinkindern ab. „Malaria verläuft bei Kleinkindern oft schwer und untypisch. Bei Kindern unter drei Monaten kann Malaria beispielsweise auch ohne Fieber auftreten“, so der Kinderarzt Dr. Mathias Wagner. Auf keinen Fall sollten Familien in die Hochrisiko-Malariagebiete auf den indonesischen Sunda-Inseln östlich von Lombok bis Papua-Neuguinea und in Ost-, West- und Zentralafrika reisen. Wagner empfiehlt aber ohnehin, bei der Wahl des Reiseziels tropische Regionen mit kleinen Kindern ganz zu meiden. Denn sie sind weniger anpassungsfähig an Hitze, empfindlicher gegenüber UV-Strahlung und häufiger von schwerwiegenden Durchfallerkrankungen betroffen. Wenn die Tropen-Reise mit kleinen Kindern - etwa aus familiären oder beruflichen Gründen unvermeidbar ist, sollten Kinderärzte den Impfstatus prüfen. In solchen Fällen übernehmen die meisten Krankenkassen auch die Kosten für Reiseschutzimpfungen.

www.crm.de 